\title{
Metabolic monitoring of psychiatric patients on second-generation antipsychotics
}

\author{
Maria Markopoulou*, Olga Georgiadou, Keranio Tsiftsoglou and \\ Konstantinos Bobotas
}

Address: Psychiatric Hospital of Thessaloniki, Thessaloniki, Greece

* Corresponding author

from International Society on Brain and Behaviour: 3rd International Congress on Brain and Behaviour

Thessaloniki, Greece. 28 November - 2 December 2007

Published: 17 April 2008

Annals of General Psychiatry 2008, 7(SuppI I):S203 doi:I0.I I86/I744-859X-7-SI-S203

This abstract is available from: http://www.annals-general-psychiatry.com/content/7/SI/S203

(C) 2008 Markopoulou et al.; licensee BioMed Central Ltd.

\section{Background}

The current literature suggests that psychiatric patients have increased mortality and morbidity rates compared with the general population, primarily due to cardiovascular disease. There is increasing evidence that the use of second-generation antipsychotics is associated with an elevated risk in the appearance of metabolic abnormalities, which promote the risk of cardiovascular disease. Abdominal obesity seems to play a contributory role in the conferring risk for hyperglycemia and dyslipidaemia.

\section{Materials and methods}

40 patients, all males, who are now hospitalized in the Psychiatric Hospital of Thessaloniki, were studied. Their mean age is 43 years old (25-78) and they are all on treatment for at least 1 year with second-generation antipsychotics. 33 are heavy smokers and only one exercise twice a week.

\section{Results}

The mean waist circumference is $109.1 \mathrm{~cm}$ (ranging from 85 to $131 \mathrm{~cm})$ and for $32(80 \%)$ of them is above $102 \mathrm{~cm}$. The mean BMI is 29.5 and in $36(90 \%)$ cases is above 25 (BMI>25=overweight). 6 (15\%) of them have high glucose level $(>110 \mathrm{mg} / \mathrm{dl}), 18(30 \%)$ have high total cholesterol $(>200 \mathrm{mg} / \mathrm{dl})$ and the mean blood pressure is estimated about $130 / 85 \mathrm{mmHg}$. 14 patients have triglycerides above normal $(>150 \mathrm{mg} / \mathrm{dl})$ and 8 have low HDL levels $(<40 \mathrm{mg} / \mathrm{dl})$. 8 patients need antihypertensive, 4 hypoglycemic and 2 hypolipidemic drugs. In sum, 14 patients (35\%) need treatment for the metabolic disturbances, probably caused by the use of the SGAs.

\section{Conclusions}

Literature review and evidence from our study show the important role of weight-gain in psychiatric patients, as it is associated with a variety of adverse physiological effects, including changes in plasma glucose and lipid levels. Therefore, ongoing monitoring for patients who are being treated with SGAs and careful selection of treatment in high-risk patients is needed.

\section{References}

I. North American Association for the Study of Obesity: Consensus development conference on antipsychotic drugs and obesity and diabetes. Diabetes Care 2004, 27:596-60I.

2. Davis JM, Chen $N$ : Old versus new: weighing the evidence between the first- and second-generation antipsychotics. Eur Psychiatry 2005, 20:7-14.

3. Meyer JM: Novel antipsychotics and severe hyperlipidemia. J Clin Psychopharmacol 200I, 21:369-74. 